\title{
Efficacy of splint therapy on Pain in the Treatment of Internal Derangement of TMJ-A clinical study
}

\author{
Altaf Malik', Shabnum Majeed ${ }^{2}$ \\ 'Govt Medical College Baramulla \\ ${ }^{2}$ Health and Medical Education Department JK
}

\section{A B S T R A C T}

\begin{abstract}
Objective(s): This study was designed to investigate the efficacy of splint therapy pain in the treatment of temporomandibular joint (TMJ) internal derangement patients.

Materials and Methods: 15 males and 25 females aged between 18 to 37 years comprised the study material in the Dental Implant and Faciomaxillary centre at Bandipore (India). The patients' complaints were limited mouth opening and TMJpain. Splints were given to the patients suffering from internal derangement. Clinical evaluation of the patients was done before the procedure, and 1 week and 3 months after postoperatively. Intensity of TMJ pain was recorded at each follow-up visit.

Results: There was significant reduction in pain scores in the post-operative period.

Conclusions: Splint therapy is simple and safe procedure for the patients of internal derangement with closed lock for improving mouth opening and decreasing pain.

Key words: Internal derangement;splint, TMJ

JMS: 2019;22(1):49-53 DOl:https://doi.org/10.33883/jms.v22i2.390
\end{abstract}

\section{INTRODUCTION}

The temporomandibular joint (TMJ) plays a vital role in basic function of stomatognathic system. Internal derangement is a general orthopaedic term implying a mechanical fault that interferes with the smooth action of a joint ${ }^{1}$. Internal derangement is a functional diagnosis, and the most common internal derangement is displacement of the disk for the $\mathrm{TMJ}^{2-7}$. The intra articular disk of TMJcan displace in an anterior, anterolateral, or anteromedial direction. The posterior band of the disk prolapses anteriorly, relative to the superior surface of the condyle, instead of remaining in position between the condyle and glenoid fossa. With the result, the condyle is positioned

\begin{tabular}{l|l}
\multicolumn{2}{c}{ Access this article online } \\
\hline
\end{tabular}

under the posterior disk attachment rather than under the disk, and the condyle closes on the posterior attachment (bilaminar zone or retrodiskal tissues) rather than on the disk itself. The central thin part of the disk lies inferior to the articular tubercle. Studies have shown that the disk frequently is also displaced in a medial or lateral direction ${ }^{8-}$ ${ }^{11}$. It is rare to have posterior disk displacement but is reported to occur'. Clinical trials suggested conservative

Correspondence:

Dr. AltafH Malik,

Assistant Professor , Govt Medical College Baramulla JK Email:drmalikaltaf@gmail.com

How to cite this article: Malik A, Majeed S. Efficacy of splint theraphy on Pain in the Treatment of Internal Derangement of TMJ-A clinical study. jms [Internet]. 2019May27 [cited $2019 \mathrm{M}$ ay 27 ]; 22 (2). Ava i 1 ab le from: http://www.jmsskims.org/index.php/jms/article/view/390

Received: 07-02-2019 Accepted: 24-04-2019 


\section{Malik A et al Treatment of Internal Derangement of TMJ-A}

measures, splint therapy, arthrocentesis, arthroscopic lysis and lavage, and arthrotomy are effective on TMJ related signs and symptoms in terms of therapy ${ }^{12}$. One method used to treat dysfunction of temporomandibular joint and muscles of the chewing system is occlusal splint therapy ${ }^{13,14}$. The occlusal splint therapy achieves neuromuscular balance in the chewing system and reduces the damage caused by parafunctional habits. ${ }^{(13,15)}$ The splint therapy is reversible and noninvasive in nature. It is recommended as initial treatment. The symptoms may be reduced if the splint is designed as per the etiology of the disease of the joint system $^{16,17}$. The occlusal splints commonly used in the treatment of temporomandibular disorders include stabilization splints and anterior repositioning splints ${ }^{16}$. The stabilization splints are usually preferred for patients with muscle hyperactivity and can be used in patients with bruxism and other parafunctional habits ${ }^{15,16}$. They can also be used in patients with local sensitization or chronic myalgia. In addition, this splint can be used to treat patients with retro discitis, which manifests after trauma, to reduce the forces on the damaged tissue and enable more effective healing ${ }^{13,16}$. Condylar disc irregularities are also treated with stabilization splints ${ }^{16}$.

\section{MATERIALS AND METHODS:}

The present study was carried out in the Dental Implant and Faciomaxillary centre Bandipore (JK India).A total of 40 patients were chosen for our study. This included 25 female patients and 15 male patients. The age ranged from 18 to 40years. The detailed examination and radiographic investigations in the form of magnetic resonance imaging were done and all the patients diagnosed with temporomandibular joint internal derangement with closed lock were selected for the study. The study was approved by the chairman of Dental implant and Faciomaxillary centre Bandipore .A written and verbal consent was obtained from the patients for treatment and associated complications, after the treatment outcome was fully explained to them. The study was conducted according to Helsinki Declaration. Visual Analogue Scale was used to score pain and the grading was done from 1 to 10 where 1 denoted no pain at all and 10 denoted very severe pain. These values were recorded pre-operatively, at 1 week and after 3 months post -operatively. The mouth opening was recorded in millimetres $(\mathrm{mm})$. The patients with joint pathologies and medically compromised patients were excluded from the study; only patients with recent onset less than one month of internal derangement were included in the study. The patients with any occlusal abnormality were excluded from the study.

Procedure: The impression of both maxillary and mandibular arches was recorded with alginate, and bite registration and articulation was done after auriculotemporal nerve block to relieve the pain. The fabrication of maxillary full coverage occlusal splint was carried out with hot-cured, clear, hard acrylic resin, by indirect laboratory technique, which minimized dental chair time and could bemore accurate, and well finished in comparison todirect technique. The splint was fitted to the maxillary teeth with total stability and retention; splint thickness did not exceed the interocclusal clearance (free way space). The occlusal surface of the splint was flattened and polished. All the posterior mandibular buccal cusps were kept in centric occlusion. Patients were asked to wear the splint full time except during eating and brushing their teeth. The other therapies were withheld during this period. The measurements were taken beforeand after week and at 3 month period and no recalribation was done of the splint.

\section{RESULTS}

All the patients were observed for 3 months .All the data was entered into master chart and subjected to statistical analysis. SPSS software (SPSS,15 Inc, Chicago, II, USA)was used to evaluate the results. Mann Whitney $U$-test and odds ratio (OR) were used. The pre-operative mouth opening ranged from 18 to $27 \mathrm{~mm}$ with a mean of $23.7 \mathrm{~mm}$ (Table 1). The VAS pain score ranged from 4 to 8 (table 2).The post operative maximum mouth opening ranged from 27 to $37 \mathrm{~mm}$ at $1 \mathrm{wk}$ with a mean of $33.475 \mathrm{~mm}$ and same increased to a range of 32 to $46 \mathrm{~mm}$ with a mean of 41.05 mmat 3 month follow-up(table 1 ) p value $<0.05$. On follow up the VAS score decreased to a range of 1 to 4 (mean2.45) at $1 \mathrm{wk}$ then to 1 to 2 (mean 1.225)at 3 month follow up(table2) with a $\mathrm{p}$ value $<0.05$. All the patients noticed improvement in their chief complaints. No complications were recorded.

\section{DISCUSSION}

The various types of occlusal appliances with unique designs according to the type of disorder are exploited to cure and rehabilitate the patients with TMJ disorders. The 


\section{Malik A et al Treatment of Internal Derangement of TMJ-A}

indications and precautions are tailored according to the joint disorder and are followed after comprehensive clinical and radiographic examination of the joint and masticatory system. In our study, mean VAS scores was 6.45 and mean MMO was $23.7 \mathrm{~mm}$ before treatment. In the post treatment phase the mean VAS pain score dropped to 2.45at 1 week and then to 1.225 at 3 month period which is statically significant with a $\mathrm{p}$ value of $<0.05$, whereas mean mouth opening improved to $33.475 \mathrm{~mm}$ at 1 week and to mean value of $41.05 \mathrm{~mm}$ at 3 month time period, which indicates significant improvement in patient symptoms and complaints. The mean increase in mouth opening was statically significant with $p$ value of $<0.05$.

The study suggests that splint acted well in improving the mouth opening and reduced the pain of internal derangement, and is in agreement with Boero ${ }^{18}$ who demonstrated an improvement in $82 \%$ of 170 TMJ patients who were wearing stabilization appliance. The results of treated group suggests that the reduction in pain and dysfunction plays an important role in improving the patient's psychological functioning, equilibrating the depression, anointment and behavioral changes developed bywearing a new oral appliance. The improvement of $8 \%$ subjects in the control group in Boero's study tends to corroborate the general remodeling ability of the joint hard and soft tissues and enhances the idea that TMJ is one of the most accommodating joint in the body, with the aid of splinting muscle action ${ }^{18}$. The significant improvement in pain and mouth opening mostly relates to the free mandibular movement patient is able to perceive after wearing the splint, as well as immediate posterior disoclusion in all mandibular movement. The possible mechanisms by which the splint works include ${ }^{18}$

1. Reduction in para functional activity.

2. Provide an occlusion relationship considered optimal for the patient. When the splint is in place it creates neuromuscular balance by eliminating occlusal interference and producing a degree of tactile afferent impulses from the periodontal proprioceptive fibers, and keeping the condyle in their most musculoskeletal stable position at the time that the teeth are contacting evenly and simultaneously.3. Reduction in pain and normal mouth opening helps in elimination of muscle splinting.
4. Recapturing of the disc due to splints helps in the normal movement of the disc due to release of adhesions which is true of most of the internal derangements.

\section{CONCLUSION}

The present study shows that conservative splint therapy should be the first approach in the treatment of TMJ disorders. The splint design of hard acrylic, full coverage and maxillary occlusal splint seems to be effective and offer superior improvement in physical symptoms particularly with pain and reduces tenderness of masticatory muscles.

\section{Conflict of interest : None}

\section{Financial Source: Nil \\ REFRENCES}

1. Adams JC, Hamblen DL. Outline of Orthopedics, 13thed. London:Churchill Livingstone, 2001;135.

2. Eriksson L, Westesson PL. Clinical and radiological study of patients with anterior disc displacement of the temporomandibular joint. Swed Dent J 1983; 7:5564.

3. Katzberg RW, Dolwick MF, Helms CA, et al. Arthrotomography of the temporomandibular joint. AJR 1980;134:9951003.

4. Westesson PL. Double-contrast arthrography and internal derangementof the temporomandibular joint. Swed Dent J Suppl 1982;13:157.

5. Wilkes $\mathrm{CH}$. Arthrography of the temporomandibular joint in patients with the TMJ pain-dysfunction syndrome. Minn Med 1978;61:645652.

6. Wilkes $\mathrm{CH}$. Structural and functional alterations of the temporomandibular joint. Northwest Dent 1978;57:287294.

7. Wilkes $\mathrm{CH}$. Internal derangements of the temporomandibular joint. Arch Otolaryngol 1989;115:469477.

8. Brooks SL, Westesson PL. Temporomandibular joint: value of coronal MR images. Radiology 1993; 188:317321.

9. Katzberg RW, Westesson PL, Tallents RH, et al. Temporomandibular joint: magnetic resonance assessment of rotational and sideways disc displacements. Radiology 1988;169:741748.

10. Liedberg J, Westesson PL. Sideways position of the 
Malik A et al Treatment of Internal Derangement of TMJ-A

temporomandibular joint disk: coronal cryosectioning of fresh autopsy specimens. Oral Surg Oral Med Oral Pathol 1988;66:644649.

11. Liedberg J, Westesson PL, Kurita K. Sideways and rotational displacement of the temporomandibular joint disk: diagnosis by arthrography and correlation to cryosectional morphology. Oral Surg Oral Med Oral Pathol 1990;69:757763.

12. Sainath Matsa, VB Krishna Kumar Raja, Siddharth Bhalerao. Temporomandibular joint arthrocentesis for closed lock - A prospective analysis of 10 consecutive cases. SRM University Journal of Dental Sciences Volume 1, Issue 3, October - Decembret 2010.

13. Ferreira FM, Cezar Simamoto-Junior P, Soares CJ, Ramos A, Fernandes- Neto AJ (2017) Effect of Occlusal Splints on the Stress Distribution on the Temporomandibular Joint Disc. Braz Dent J 28(3): 324-329.

14. Algabri RS, Alqutaibi AY (2017) No Evidence Suggests that the Clinical Effectiveness of Conventional Occlusal Splints is Superior to That of Psychosocial Interventions for Myofascial

Table 1(Mouth opening in millimetres $\mathrm{mm}$ )

\begin{tabular}{|c|c|c|c|}
\hline Patient & $\begin{array}{l}\text { Preoperative } \\
\text { mouth } \\
\text { opening }(\mathrm{mm})\end{array}$ & $\begin{array}{l}\text { Post-operative } \\
\text { mouth } \\
\text { opening(1wk in } \\
\text { mm) }\end{array}$ & $\begin{array}{l}\text { Post- } \\
\text { operative } \\
\text { mouth } \\
\text { opening } \\
\text { (3months } \\
\text { in mm) }\end{array}$ \\
\hline 1 & 27 & 35 & 45 \\
\hline 2 & 21 & 33 & 42 \\
\hline 3 & 19 & 30 & 42 \\
\hline 4 & 23 & 34 & 42 \\
\hline 5 & 26 & 35 & 44 \\
\hline 6 & 23 & 33 & 41 \\
\hline 7 & 25 & 37 & 43 \\
\hline 8 & 27 & 35 & 43 \\
\hline 9 & 19 & 32 & 39 \\
\hline 10 & 20 & 36 & 40 \\
\hline 11 & 25 & 33 & 43 \\
\hline 12 & 24 & 36 & 44 \\
\hline 13 & 27 & 36 & 45 \\
\hline 14 & 24 & 36 & 42 \\
\hline 15 & 18 & 27 & 32 \\
\hline 16 & 19 & 29 & 39 \\
\hline 17 & 26 & 37 & 43 \\
\hline 18 & 23 & 33 & 45 \\
\hline 19 & 27 & 37 & 46 \\
\hline 20 & 26 & 27 & 41 \\
\hline
\end{tabular}

Tempromandibular Disorders Pain. J Evid Based Dent Pract 17(4): 399-401.

15. Okeson JP (2009) Critical commentary 1: Evaluation of the research diagnostic criteria for temporomandibular disorders for the recognition of an anterior disc displacement with reduction. J Orofac Pain 23(4): 312-315.

16. Al-Ani MZ, Davies SJ, Gray RJ, Sloan P, Glenny AM (2004)Stabilisation splint therapy for temporomandibular pain dysfunction syndrome. Cochrane Database Syst Rev 1: 1-24.

17. Liu MQ, Lei J, Han JH, Yap AU, Fu KY (2017) Metrical analysis of disc-condyle relation with different splint treatment positions in patients with TMJ disc displacement. J Appl Oral Sci 25(5): 483489.

18. Wajnaa F. Qasim. The Effectiveness of Occlusal Splint Therapy in Treatment of Iraqi Temporomandibular Disorder (TMD) Patients. J Med J 2006; December: Vol. 40 (4) http///ar.ju.edu.jo/jmj

\begin{tabular}{|l|l|l|l|}
\hline 21 & 19 & 32 & 41 \\
\hline 22 & 27 & 34 & 42 \\
\hline 23 & 20 & 35 & 39 \\
\hline 24 & 23 & 34 & 41 \\
\hline 25 & 27 & 36 & 40 \\
\hline 26 & 25 & 33 & 40 \\
\hline 27 & 20 & 32 & 38 \\
\hline 28 & 26 & 34 & 41 \\
\hline 29 & 21 & 27 & 39 \\
\hline 30 & 27 & 36 & 41 \\
\hline 31 & 25 & 32 & 39 \\
\hline 32 & 24 & 34 & 41 \\
\hline 33 & 23 & 32 & 40 \\
\hline 34 & 19 & 34 & 39 \\
\hline 35 & 26 & 32 & 40 \\
\hline 36 & 25 & 32 & 38 \\
\hline 37 & 27 & 35 & 40 \\
\hline 38 & 26 & 34 & 40 \\
\hline 39 & 25 & 36 & 41 \\
\hline 40 & 24 & 34 & 41 \\
\hline Mean & $23.7 \mathrm{~mm}$ & $33.475 \mathrm{~mm}$ & $41.05 \mathrm{~mm}$ \\
& & & $(\mathrm{p}$ value \\
& & & $<0.05$ \\
& & & Significant \\
\hline
\end{tabular}


Malik A et al Treatment of Internal Derangement of TMJ-A

Table 2(Pain in the TMJ on VAS scale)

\begin{tabular}{|l|l|l|l|}
\hline Patient & $\begin{array}{l}\text { Pre-op } \\
\text { pain(VAS) }\end{array}$ & $\begin{array}{l}\text { Post-op pain } \\
\text { (VAS) IWK }\end{array}$ & $\begin{array}{l}\text { Post-op } \\
\text { pain } \\
3 \text { months }\end{array}$ \\
\hline 1 & 7 & 3 & 1 \\
\hline 2 & 6 & 4 & 1 \\
\hline 3 & 5 & 2 & 1 \\
\hline 4 & 8 & 3 & 2 \\
\hline 5 & 7 & 3 & 1 \\
\hline 6 & 8 & 4 & 2 \\
\hline 7 & 6 & 2 & 1 \\
\hline 8 & 6 & 2 & 1 \\
\hline 9 & 8 & 3 & 1 \\
\hline 10 & 5 & 1 & 1 \\
\hline 11 & 7 & 3 & 1 \\
\hline 12 & 8 & 3 & 2 \\
\hline 13 & 6 & 2 & 1 \\
\hline 14 & 5 & 1 & 1 \\
\hline 15 & 7 & 3 & 1 \\
\hline 16 & 8 & 4 & 1 \\
\hline 17 & 5 & 3 & 1 \\
\hline 18 & 6 & 1 & 1 \\
\hline 19 & 8 & 2 & 1 \\
\hline 20 & 7 & 3 & 1 \\
\hline & & & \\
\hline
\end{tabular}

\begin{tabular}{|l|l|l|l|}
\hline 21 & 5 & 2 & 2 \\
\hline 22 & 8 & 3 & 1 \\
\hline 23 & 6 & 2 & 1 \\
\hline 24 & 7 & 2 & 1 \\
\hline 25 & 7 & 3 & 2 \\
\hline 26 & 5 & 2 & 1 \\
\hline 27 & 5 & 1 & 1 \\
\hline 28 & 6 & 2 & 2 \\
\hline 29 & 8 & 3 & 2 \\
\hline 30 & 7 & 2 & 1 \\
\hline 31 & 4 & 1 & 1 \\
\hline 32 & 5 & 2 & 1 \\
\hline 33 & 6 & 3 & 1 \\
\hline 34 & 8 & 5 & 2 \\
\hline 35 & 6 & 2 & 1 \\
\hline 36 & 7 & 2 & 1 \\
\hline 37 & 5 & 1 & 1 \\
\hline 38 & 6 & 2 & 1 \\
\hline 39 & 6 & 3 & 2 \\
\hline 40 & 8 & 3 & 1 \\
\hline Mean & 6.45 & 2.45 & $1.225(\mathrm{p}$ \\
& & & value $<0.05$ \\
& & & significant $)$ \\
\hline
\end{tabular}

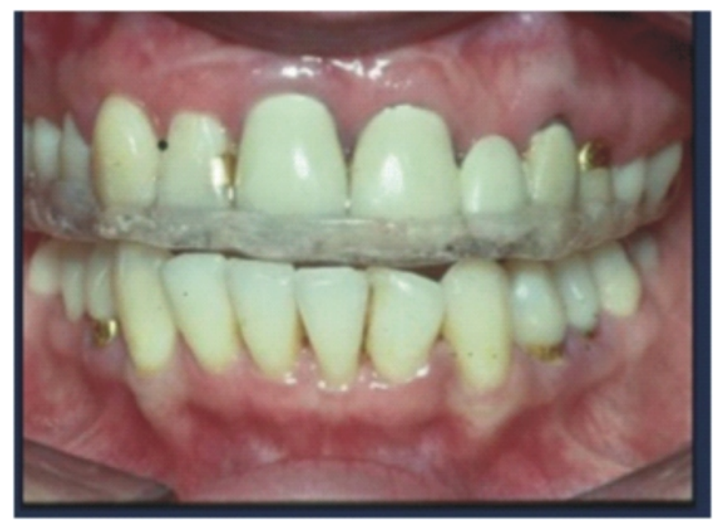

Fig 1: The splint

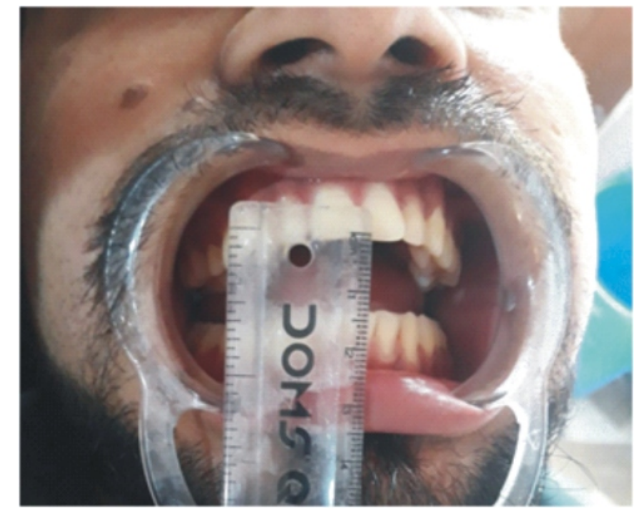

Fig 2: Mouth opening before splint therapy

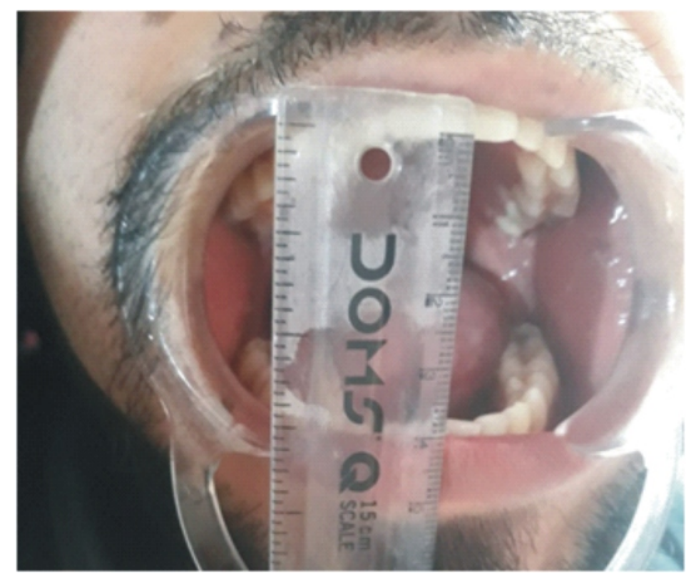

Fig3: Mouth opening after the splint therapy 